\title{
BMJ Open Risk factors for feelings of sadness and suicide attempts among cancer survivors in South Korea: findings from nationwide cross-sectional study (KNHANES IV-VI)
}

\author{
Jeewoong Choi, ${ }^{1}$ Mijo Lee, ${ }^{2}$ Myung Ki, ${ }^{3}$ Ju-Yeong Lee, ${ }^{1}$ Yeong-Jun Song, ${ }^{1}$ \\ Miram Kim, ${ }^{1}$ Sunyoung Lee, ${ }^{4}$ Soonjoo Park, ${ }^{5}$ Jiseun Lim ${ }^{1}$
}

To cite: Choi J, Lee M, Ki M, et al. Risk factors for feelings of sadness and suicide attempts among cancer survivors in South Korea: findings from nationwide cross-sectional study (KNHANES IV-VI). BMJ Open 2017;7:e016130. doi:10.1136/ bmjopen-2017-016130

- Prepublication history for this paper is available online. To view these files, please visit the journal online (http://dx.doi org/10.1136/bmjopen-2017016130).

$\mathrm{JC}$ and $\mathrm{ML}$ contributed equally.

Received 26 January 2017 Revised 17 October 2017 Accepted 20 October 2017

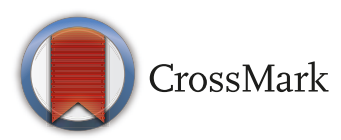

For numbered affiliations see end of article.

Correspondence to Professor Jiseun Lim; jslim@eulji.ac.kr

\section{ABSTRACT}

Introduction As the number of cancer survivors is rapidly increasing with the increased incidence of the disease and improved survival of patients, the prevalence of, and risk factors for, mental health problems and suicidality among cancer survivors should be examined.

Methods and analysis Using data obtained from the Korean National Health and Nutrition Examination Survey (2007-2013), we examined 1285 and 33772 participants who had been and never been diagnosed with cancer, respectively. We investigated the risks of feelings of sadness and suicide attempts among cancer survivors and general population and examined differences in the risks of cancer survivors among subgroups according to cancerrelated characteristics.

Results The median age of survivors at the time of the survey and at diagnosis was 63 and 54 years, respectively. After adjusting for sex, level of education, household income, occupation, marital status, cancer type, current status of treatment, age at diagnosis and years since diagnosis, the risk of suicide attempts was significantly higher in participants diagnosed with cancer before 45 years of age compared with those diagnosed at 45-64 years (adjusted $\mathrm{OR}=3.81,95 \% \mathrm{Cl} 1.07$ to $13.60, \mathrm{P}=0.039$ ), and the higher risk of suicide attempts with borderline significance was found in those for whom more than 10 years had passed since diagnosis compared with those for whom the diagnosis was made only $2-10$ years ago (adjusted OR=3.38, 95\% $\mathrm{Cl} 0.98$ to $11.70, \mathrm{P}=0.055$ ). However, feelings of sadness were not significantly associated with any cancer-related characteristic. Conclusion Our results reveal an increased risk of suicide attempts among cancer survivors diagnosed early in life and in those for whom more than 10 years has passed since the diagnosis, suggesting the need for intensive monitoring and support for mental health problems and suicidal risks in this population.

\section{INTRODUCTION}

The number of cancer survivors has increased recently in South Korea due to early detection and advances in diagnosis

\section{Strengths and limitations of this study}

- This study is the first to assess the prevalence of, and risk factors for, feelings of sadness and suicide attempts among survivors of all types of cancer.

- The study participants were 1285 cancer survivors who are aged $30-84$ years participating in nationwide survey of the health and nutritional status of non-institutionalised Korean individuals.

- Because the risk for suicide attempts was measured among prevalent cancer patients, our results cannot be directly interpreted with respect to the suicide risk of incident patients with cancer.

- Despite the large sample size, few cancer survivors attempted suicide, resulting in insufficient examination of statistical significance of differences in suicide risk according to participant characteristics.

and treatment, as well as to the increasing incidence of the disease. ${ }^{1}$ Mental health is an important issue among cancer survivors and is closely related to their overall quality of life. ${ }^{2}$ Moreover, an increased risk of suicide has been reported consistently worldwide. ${ }^{3-19}$

A number of cohort studies have revealed that the risk of suicide increases immediately after cancer diagnosis. ${ }^{3-18}$ However, a growing body of evidence suggests that cancer survivors suffer from chronic stress related to physical problems, fatigue, psychological distress and social and economic burden for a prolonged period of time. ${ }^{20-31}$ Suicidal behaviour in longterm cancer survivors may be indicative of a high risk of completing suicide and of severe emotional or physical suffering.

Recently, suicide has become an important issue from the perspective 
Table 1 Characteristics of cancer survivors

\begin{tabular}{|c|c|c|}
\hline & $\mathbf{N}$ & $\%$ \\
\hline 1285 & \multicolumn{2}{|c|}{100.0} \\
\hline
\end{tabular}

\begin{tabular}{lrr}
$30-44$ & 120 & 9.3 \\
$45-64$ & 561 & 43.7 \\
$\geq 65$ & 604 & 47.0 \\
\hline
\end{tabular}

Sex

\begin{tabular}{|lll|}
\hline Male & 467 & 36.3 \\
\hline Female & 818 & 63.7 \\
\hline Education level & & \\
\hline Low & 566 & 44.1 \\
\hline Middle & 435 & 33.9 \\
\hline High & 283 & 22.0 \\
\hline Household income & & \\
\hline Low & 402 & 31.9 \\
\hline Mid-low & 317 & 25.1 \\
\hline Mid-high & 264 & 20.9 \\
\hline High & 278 & 22.1 \\
\hline
\end{tabular}

Occupation

\begin{tabular}{lrr} 
Manager or office job & 117 & 9.1 \\
\hline Service or sales & 97 & 7.6 \\
\hline Physical work & 269 & 21.0 \\
\hline Not employed & 800 & 62.4 \\
Marital status & & \\
\hline Married & 1000 & 77.9 \\
Single & 20 & 1.6 \\
\hline Widowed & 203 & 15.8 \\
\hline Divorced or separated & 61 & 4.8 \\
Cancer type & & \\
\hline Stomach & 259 & 20.2 \\
\hline Liver & 40 & 3.1 \\
Colon & 135 & 10.5 \\
Breast & 173 & 13.5 \\
Cervical & 175 & 13.6 \\
\hline Lung & 38 & 3.0 \\
\hline Others & 465 & 36.2
\end{tabular}

Current status of treatment

\begin{tabular}{|c|c|c|}
\hline No & 764 & 64.7 \\
\hline Yes & 416 & 35.3 \\
\hline \multicolumn{3}{|c|}{ Age at diagnosis (years) } \\
\hline $15-44$ & 311 & 24.3 \\
\hline $45-64$ & 673 & 52.7 \\
\hline$\geq 65$ & 294 & 23.0 \\
\hline \multicolumn{3}{|c|}{ Years since diagnosis } \\
\hline $0-1$ & 227 & 17.8 \\
\hline $2-5$ & 442 & 34.6 \\
\hline $6-10$ & 227 & 17.8 \\
\hline $11-14$ & 171 & 13.4 \\
\hline$\geq 15$ & 211 & 16.5 \\
\hline
\end{tabular}

of Korean public health. The suicide rate in South Korea (hereafter referred to as Korea) has increased drastically during the past two decades and has been the highest among Organization for Economic Co-operation and Development countries since the early 2000s. ${ }^{32}$ Moreover, in patients diagnosed with cancer, the crude rate of suicide was as high as 88.7 per 100000 person-years. The suicide rate in cancer survivors is twice that of the general population in Korea ( standardised mortality ratio $(\mathrm{SMR})=2.00$ ) and more than twice that of patients with cancer in the USA (31.4 per 100000 person-years). ${ }^{5}{ }^{12}$ From these data, we conclude that Korean cancer survivors likely suffer more from substantial mental health problems than both the general population of Korean and cancer survivors in other countries. Therefore, from the perspective of public health, it is imperative to cross-sectionally identify the levels of psychiatric distress and suicidality, as well as their risk factors, among Korean cancer survivors.

In addition, previous studies investigating the risk of suicide in cancer survivors have focused mainly on cancer-related characteristics; few studies have considered sociodemographic characteristics, although a higher risk of mental health problems among cancer survivors has been associated with a low socioeconomic status. $223133-35$

Therefore, we investigated the risks of feelings of sadness and suicide attempts as indicators of psychiatric distress and suicidal behaviour, respectively, among Korean cancer survivors using data obtained from a nationwide cross-sectional study. We examined potential differences in the risks for feelings of sadness and suicide attempts among subgroups according to sociodemographic status and cancer-related characteristics.

\section{MATERIALS AND METHODS Data source}

Data on cancer survivors and a non-cancer population were obtained from the Korean National Health and Nutrition Examination Survey (KNHANES), a nationwide survey of the health and nutritional status of non-institutionalised Korean individuals. Briefly, a two-stage stratified cluster sampling method was used to secure data representation of Korean population. To illustrate, in the first stage, 192 primary sampling units (PSUs) were selected from about 2000000 geographically separated PSUs in the country. Then, all individuals ( $\geq 1$ year) of 20 target households were selected from each selected PSU (details on the survey profile is available elsewhere) ${ }^{36}$ As suicide attempts are very rare, even in cancer survivors, we pooled three waves of KNHANES data in this study: IV (20072009), V (2010-2012) and VI (2013), where the information on variables of primary interest were available. 
Table 2 Crude and adjusted ORs of feelings of sadness and suicide attempts among cancer survivors compared with the non-cancer group

\begin{tabular}{|c|c|c|c|c|c|c|c|c|c|c|c|}
\hline \multirow[b]{2}{*}{ Group } & \multirow[b]{2}{*}{$\begin{array}{l}\text { Sample } \\
\text { size }\end{array}$} & \multicolumn{5}{|c|}{ Feelings of sadness } & \multicolumn{5}{|c|}{ Suicide attempts } \\
\hline & & $\mathbf{N}$ & $\%$ & $\begin{array}{l}\text { Crude OR } \\
(95 \% \mathrm{Cl})\end{array}$ & $\begin{array}{l}\text { Adjusted OR* } \\
(95 \% \mathrm{Cl})\end{array}$ & $\mathrm{P} †$ & $\mathbf{N}$ & $\%$ & $\begin{array}{l}\text { Crude OR } \\
(95 \% \mathrm{Cl})\end{array}$ & $\begin{array}{l}\text { Adjusted OR* } \\
(95 \% \mathrm{Cl})\end{array}$ & P† \\
\hline $\begin{array}{l}\text { Cancer } \\
\text { survivors }\end{array}$ & 1285 & 258 & 20.1 & 1.58 (1.33 to 1.87$)$ & 1.29 (1.08 to 1.55$)$ & 0.005 & 20 & 1.6 & 1.95 (1.11 to 3.42$)$ & 1.65 (0.92 to 2.96$)$ & 0.094 \\
\hline
\end{tabular}

${ }^{*}$ Adjusted for age, sex, level of education, household income, occupation, marital status and year of survey †P value for adjusted $O R$.

\section{Study sample}

Among 38080 adults aged 30-84 years participating in KNHANES 2007-2013, the number of cancer survivors and of the non-cancer population were $1293(3.4 \%)$ and 36787 (96.6\%), respectively. After excluding participants who did not provide answers regarding their feelings of sadness or suicide attempts, $1285(99.4 \%)$ cancer survivors and 33772 (91.8\%) non-cancer participants were included in the final analysis.

\section{Measurements}

\section{Outcome variables}

In this study, feelings of sadness and suicide attempts were selected as the main outcome variables. In KNHANES IV and V, suicidal ideation was assessed by the question 'Have you ever felt like dying in the past year?'. However, in Korean society, the expression 'feel like dying' is used casually. Therefore, 'to feel like dying' does not necessarily equate to suicidal ideation. In the sixth wave of KNHANES, the question regarding suicidal ideation was changed to 'Have you ever seriously thought about committing suicide in the past year?'. This change reflects the problem with the previous question with respect to measuring suicidal ideation. Therefore, we excluded suicidal ideation as the main outcome. Feelings of sadness and suicide attempts were measured by responses (yes or no) to the following questions: 'During the recent 12 months, have you ever felt so sad or hopeless almost every day for 2 weeks in a row that you stopped doing some usual activities?' and 'In the last 12 months, have you attempted suicide?', respectively.

\section{Independent variables and covariates}

Cancer survivorship was measured by the question 'Have you ever been diagnosed with cancer?'. Considering prevalence, stomach, liver, colon, breast, cervical, and lung cancer were grouped as an individual category and all other cancers such as small intestine, kidney and bladder were grouped as other category.

Among the 1285 cancer survivors, 51 had been diagnosed with multiple primary cancers. The type and date of the earliest cancer were assigned for the multiple primary cancer cases. If two or more cancer types occurred in the same year, the type and date of more severe cancer was assigned to the case in the order of lung, liver, colon, stomach, breast, cervical and other cancer, according to annual cancer mortality rate in Korea ${ }^{37}$; this rule was applied to eight patients. For example, two patients diagnosed with stomach and colon were assigned to colon cancer, because in Korea, stomach cancers show relatively better prognosis than colon cancer.

Cancer-related variables were cancer type (stomach, liver, colon, breast, cervical, lung or other), currently receiving treatment (yes or no), age at diagnosis (30-44, 45-64 or 65+years) and years since diagnosis $(0-1,2-5,6-10$ or $>10$ years $)$.

The prevalence of feelings of sadness and suicide attempts among cancer survivors was compared among subgroups classified according to sociodemographic status and cancer-related characteristics. The sociodemographic variables were age (30-44, $45-64$ or $65+$ years), sex (male or female), education level (low, middle or high), household income (low, mid-low, mid-high or high), occupation (manager or office job, service or sales, physical work or not employed) and marital status (married or single, widowed, or divorced or separated). Participants were categorised into low, middle or high education level according to different criteria for the adult $(<65$ years old) and elderly ( $\geq 65$ years old) groups. Low, middle and high education levels were defined as less than primary school graduate, middle or high school graduate and more than college graduate, respectively, in the adult group, while they were defined as less than primary school graduate, middle school graduate and more than high school graduate, respectively, in the elderly group. Household income was calculated as total monthly household income divided by the square root of the family size and categorised into quartiles according to sex and age in each survey year.

\section{Statistical analysis}

Univariate logistic regression analysis was used to investigate factors associated with feelings of sadness or suicide attempts by estimating the crude ORs and 
their 95\% CIs. The associations between general characteristics and feelings of sadness or suicide attempts were further examined after adjusting for sex, education level, household income, occupation, marital status, cancer type, current status of treatment, age at diagnosis (years) and years since diagnosis. Because there was linear dependence between age at survey, age at diagnosis and years since diagnosis (ie, years since diagnosis=age at survey - age at diagnosis), only two variables were included as covariates in the multivariate analysis. Age at diagnosis and years since diagnosis were included as covariates in the adjusted model, because they were both significant in the univariate analysis, whereas age at survey was not. Because only 20 patients attempted suicide in the current study, penalised logistic regression method, which is recommended in the case of rare event problem, was applied using firthlogit procedure of STATA in the examining the risk factors of suicide attempts with multivariable model. ${ }^{38}$

Sampling weights, which were assigned to each survey participants to be equivalent to the size of entire Korean population of the year, were constructed based on inverse of selection probabilities. Univariable and multivariable logistic regressions were conducted using PROC SURVEYLOGISTC procedure of SAS to apply complex survey sampling weights except for examining the risk factors of suicide attempts with multivariable model using firthlogit procedure. Data were analysed statistically using SAS (V.9.4) and STATA software (V.14.0). A P value $<0.05$ was considered significant.

\section{RESULTS}

Among 1285 cancer survivors, the median age (range) at the time of the survey was 63 years (30-84 years). The median age (range) at cancer diagnosis was 54 years (15-83 years) and the median age (range) after diagnosis was 5 years $(0-50$ years $)$. The percentage of female participants was $63.7 \%$. The most common type of cancer was stomach cancer (20.2\%), followed by cervical $(13.6 \%)$, breast $(13.5 \%)$ and colon cancer $(10.5 \%)$. Approximately half of all the cancer survivors were more than 65 years old, diagnosed with cancer at 45-64 years or in the past 2-10 years (table 1).

Cancer survivors showed a significantly higher prevalence of feelings of sadness and suicide attempts within the past year than the non-cancer group. The prevalences of feelings of sadness were $20.1 \%$ and $14.2 \%$ among cancer survivors and the non-cancer group, respectively (crude $\mathrm{OR}=1.58,95 \%$ CI 1.33 to 1.87 ). The prevalences of suicide attempts were $1.6 \%$ and $0.9 \%$ among cancer survivors and the non-cancer group, respectively (crude $\mathrm{OR}=1.95,95 \% \mathrm{CI} 1.11$ to 3.42). After adjusting for age, sex, level of education, household income, occupation, marital status and year of survey, cancer survivors showed a significantly higher risk of feelings of sadness than the non-cancer group (adjusted OR=1.29; 95\% CI 1.08 to $1.55, \mathrm{P}=0.005$ ) and a higher risk of suicide attempts, although the difference was not significant (adjusted $\mathrm{OR}=1.65 ; 95 \%$ CI 0.92 to $2.96, \mathrm{P}=0.094$ ) (table 2).

Participants who were female, less educated, had a low income or were not employed showed a significantly higher risk of feelings of sadness. The risk of suicide attempts was significantly lower in the participants who had mid-high level of household income compared with those who had low level of household income. Participants who had been diagnosed with cancer before 45 or after 64 years of age showed a significantly higher risk of suicide attempts than those diagnosed with cancer at 45-64years of age (table 3 ).

After adjusting for sex, level of education, household income, occupation, marital status, cancer type, current status of treatment, age at diagnosis and years since diagnosis, female and lower level of education and household income were significantly associated with higher prevalence of feelings of sadness (table 4).

After adjusting for sex, level of education, household income, occupation, marital status, cancer type, current status of treatment, age at diagnosis and years since diagnosis, the risk of suicide attempts was significantly higher in participants diagnosed with cancer before 45 years of age compared with those diagnosed at 45-64 years (adjusted OR=3.81, 95\% CI 1.07 to 13.60, $\mathrm{P}=0.039)$, and it was higher with borderline significance in patients with cancer for whom more than 10 years had passed since diagnosis compared with those for whom only 2-10 years had passed (adjusted $\mathrm{OR}=3.38$, $95 \%$ CI 0.98 to $11.70, \mathrm{P}=0.055$ ) (table 5 ).

\section{DISCUSSION}

In this study, we cross-sectionally examined the prevalence of feelings of sadness and suicide attempts within the past year among cancer survivors and their associations with cancer-related and sociodemographic characteristics. To our knowledge, this study is the first to assess the prevalence of feelings of sadness and suicide attempts among survivors of all types of cancer. The Korean cancer survivors showed a higher prevalence of feelings of sadness $(20.1 \%)$ and suicide attempts within the past year $(1.6 \%)$ than the non-cancer population (feelings of sadness: $14.2 \%$, suicide attempts: $0.9 \%$ ). Cancer survivors with less education and a low income showed a higher risk for feelings of sadness and suicide attempts, but the differences were not statistically significant in the multivariate analysis except for the significant difference of the prevalence of feelings of sadness across education and household income categories. The trends observed for feelings of sadness and suicide attempts according to age at diagnosis and time since diagnosis were similar (ie, the prevalence of sadness and suicide attempts among cancer survivors diagnosed at 15-44 years of age, and in those for whom more than 10 years had passed since the diagnosis, was higher than 


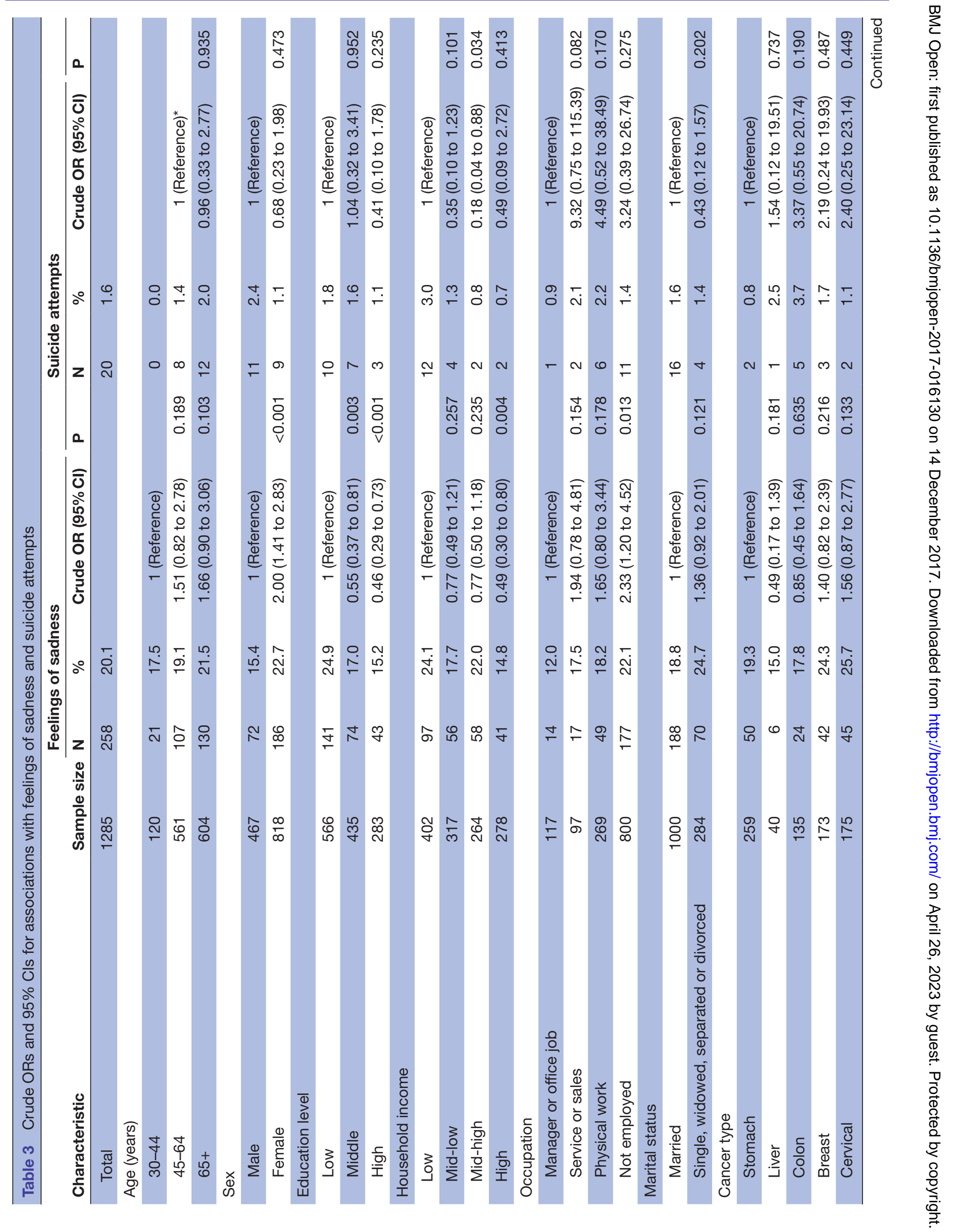




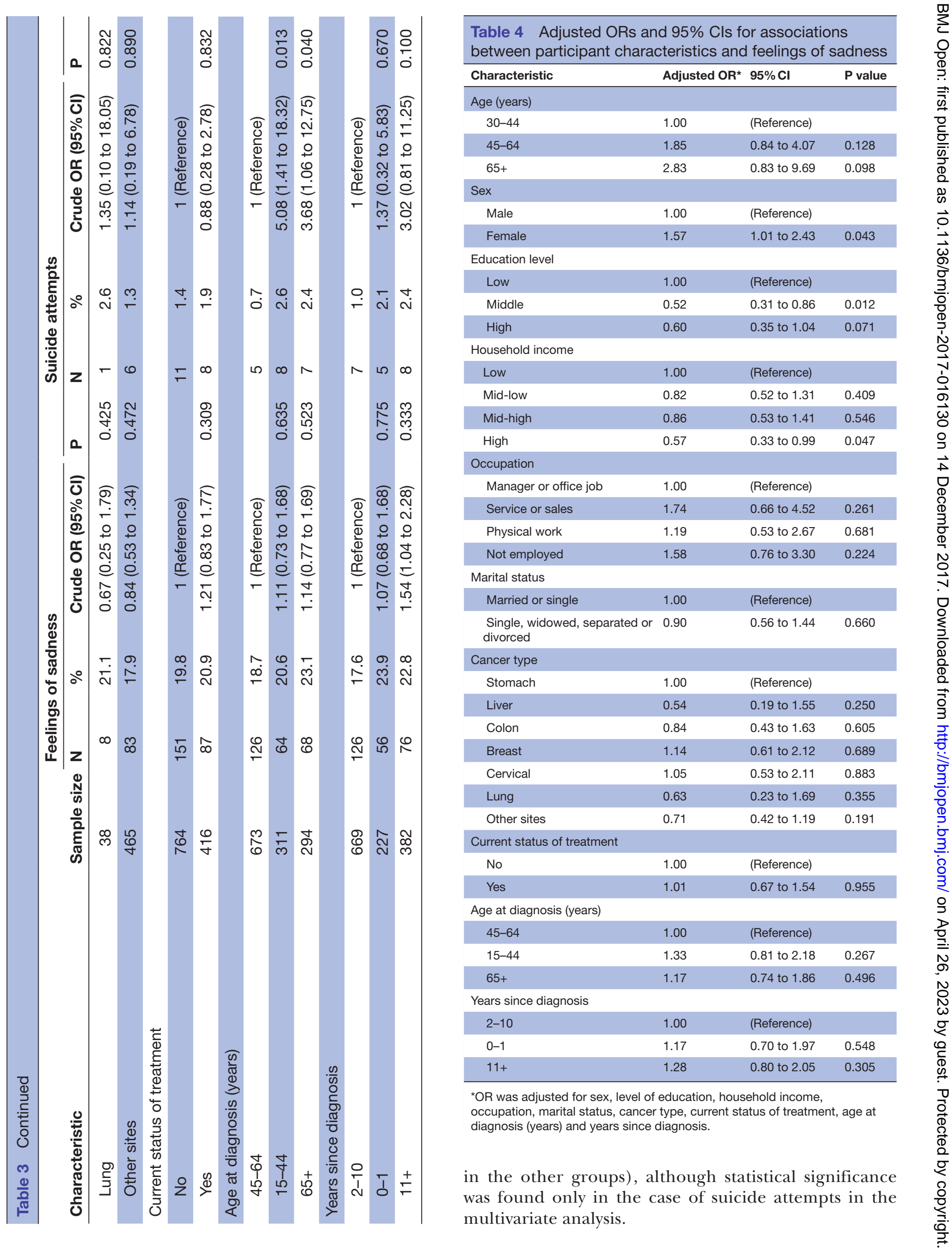


Table 5 Adjusted ORs and 95\% Cls for associations between participant characteristics and suicide attempts

\begin{tabular}{|c|c|c|c|}
\hline Characteristic & Adjusted OR* & $95 \% \mathrm{Cl}$ & $P$ value \\
\hline \multicolumn{4}{|l|}{ Age (years) $\dagger$} \\
\hline $45-64$ & 1.00 & (Reference) & \\
\hline $65+$ & 1.60 & 0.28 to 9.15 & 0.597 \\
\hline \multicolumn{4}{|l|}{ Sex } \\
\hline Male & 1.00 & (Reference) & \\
\hline Female & 0.36 & 0.10 to 1.30 & 0.117 \\
\hline \multicolumn{4}{|l|}{ Education level } \\
\hline Low & 1.00 & (Reference) & \\
\hline Middle & 1.88 & 0.60 to 5.94 & 0.282 \\
\hline High & 1.22 & 0.31 to 4.83 & 0.778 \\
\hline \multicolumn{4}{|l|}{ Household income } \\
\hline Low & 1.00 & (Reference) & \\
\hline Mid-low & 0.52 & 0.16 to 1.68 & 0.278 \\
\hline Mid-high & 0.38 & 0.08 to 1.73 & 0.212 \\
\hline High & 0.33 & 0.07 to 1.56 & 0.163 \\
\hline \multicolumn{4}{|l|}{ Occupation $\ddagger$} \\
\hline Manager, office or no job & 1.00 & (Reference) & \\
\hline Service, sales or physical work & 2.12 & 0.81 to 5.55 & 0.125 \\
\hline \multicolumn{4}{|l|}{ Marital status } \\
\hline Married & 1.00 & (Reference) & \\
\hline $\begin{array}{l}\text { Single, widowed, separated or } \\
\text { divorced }\end{array}$ & 0.95 & 0.30 to 3.01 & 0.934 \\
\hline \multicolumn{4}{|l|}{ Cancer type } \\
\hline Stomach & 1.00 & (Reference) & \\
\hline Liver & 3.68 & 0.43 to 31.20 & 0.233 \\
\hline Colon & 4.56 & 0.98 to 21.19 & 0.053 \\
\hline Breast & 4.96 & 0.70 to 35.04 & 0.108 \\
\hline Cervical & 2.34 & 0.28 to 19.53 & 0.432 \\
\hline Lung & 4.17 & 0.51 to 33.90 & 0.182 \\
\hline Other sites & 1.89 & 0.40 to 8.88 & 0.419 \\
\hline \multicolumn{4}{|l|}{ Current status of treatment } \\
\hline No & 1.00 & (Reference) & \\
\hline Yes & 2.14 & 0.72 to 6.41 & 0.173 \\
\hline \multicolumn{4}{|l|}{ Age at diagnosis (years) } \\
\hline $45-64$ & 1.00 & (Reference) & \\
\hline $15-44$ & 3.81 & 1.07 to 13.60 & 0.039 \\
\hline $65+$ & 2.55 & 0.76 to 8.53 & 0.130 \\
\hline \multicolumn{4}{|l|}{ Years since diagnosis } \\
\hline $2-10$ & 1.00 & (Reference) & \\
\hline $0-1$ & 2.38 & 0.71 to 7.96 & 0.160 \\
\hline $11+$ & 3.38 & 0.98 to 11.70 & 0.055 \\
\hline
\end{tabular}

*OR was adjusted for sex, level of education, household income, occupation, marital status, cancer type, current status of treatment, age at diagnosis (years) and years since diagnosis.

†The 45-64 years age group was set as the reference, because there were no suicide attempts within the past among cancer survivors aged 30-44 years.

$\ddagger$ The occupation variable was categorised into two groups because the model that included the four categories for this variable did not fit.

In this study, the adjusted OR for age, sex, level of education, household income, occupation, marital status and year of survey was 1.65 for suicide attempts in patients with cancer compared with the non-cancer group, while a previous cohort study reported that the SMR for suicide was 2.00 in a Korean population. ${ }^{12}$ The ratio for the prevalence of suicide attempts was lower than that for the incidence of suicide in patients with cancer compared with the general population, because patients with cancer had attempted suicide more seriously than general population; furthermore, those who committed suicide or had very severe suicidal ideation may not have been included in the cross-sectional survey.

Although no previous study has cross-sectionally examined the risk of suicide attempts among patients with all types of cancer, one previous study reported a $4.4 \%$ lifetime prevalence of suicide attempts in 226 adult survivors of childhood cancer. ${ }^{39}$ This difference between our study (prevalence $=1.6 \%$ ) and the previous study may be due to the difference in the duration of the measurement of suicide attempts (lifetime vs past year), the type of cancer survivor (only childhood cancer vs all cancers), the study field (community vs cancer survivor clinic) or the survey country (USA vs Korea).

Previous studies have reported a higher risk of mental health problems, including depression, anxiety and psychological distress, among cancer survivors with a low socioeconomic status. ${ }^{22}{ }^{31} 33-35$ However, most cohort studies examining suicide risk after cancer diagnosis have focused on the clinical characteristics of patients with cancer. The only previous cohort study to concurrently assess both the clinical and socioeconomic status (indices of deprivation) reported a non-significant effect on suicide risk of socioeconomic inequality. ${ }^{10}$ Our findings that cancer survivors who were less educated or had a low income had a higher risk of feelings of sadness and suicide attempts are consistent with those of the previous study.

The significantly higher risk of suicide attempts in cancer survivors who were diagnosed with cancer before 45 years of age, and the higher risk with borderline significance in those for whom more than 10 years had passed since diagnosis, represent an important finding of this study. Previous cohort studies have consistently reported that the risk of suicide was highest immediately after cancer diagnosis, ${ }^{3} 56810-18$ while results related to age at diagnosis have been quite variable..$^{56810-13} 1617$ Most previous studies examined potential differences in suicide risk by comparing the SMR among subgroups and primarily compared the suicide risk of subgroups relative to the general population after adjusting only for age; they did not compare the difference in suicide risk among subgroups. Two previous studies examining the suicide risk difference among subgroups using multivariate analysis reported no statistically significant heterogeneity according to age at diagnosis. ${ }^{10}{ }^{17}$ Based on the results of the present study, further research is needed to determine whether the risks of psychiatric distress and suicide are higher in cancer survivors diagnosed in their youth. 
In several previous studies of long-term cancer survivors, only the risk of suicide more than 5 years after diagnosis was examined, and there was no assessment of the risk of suicide more than 10 years after diagnosis. ${ }^{12} 1517$ This may be because cancer survivors who were diagnosed more than 5 years ago generally recognised to be completely cured and to no longer suffer from mental health problems. Only a few studies that analysed psychological distress among cancer survivors diagnosed more than 10 years ago have shown higher risks of anxiety and serious psychological distress versus survivors early in the course of cancer. ${ }^{15} 3340$ These findings are consistent with the results of the present study, in which the risks of feelings of sadness and suicide attempts were highest among cancer survivors diagnosed more than 10 years ago. The only previous cohort study to examine patients of all cancer types diagnosed more than 10 years ago reported the highest SMR during the first 5 years after diagnosis. ${ }^{5}$ However, the previous study also found that patients with several cancer types (nervous system, leukaemia, prostate and cervical) showed the highest suicide rate at 15-30 years postdiagnosis. $^{5}$

The higher risk of suicide attempts in patients with cancer diagnosed more than 10 years previously seen in this study may be associated with chronic stress. Although chronic stress related to higher suicide risk refers mainly to the social environment of adolescents persisting from childhood, such as poor family relationships and low economic status, ${ }^{30}{ }^{201}$ long-term cancer survivors can also suffer from chronic stress, including facing economic burden, pain, disability and the continuous threat of recurrence over a long period..$^{20}$ Because acute physical and mental stress occurring immediately after cancer diagnosis increases the risk of psychiatric distress and suicide, chronic stress in cancer survivors may also play an important role in increasing this risk. Further research is needed to address the problems associated with mental distress and suicidality in long-term cancer survivors. Additionally, clinicians and health authorities should remain vigilant for mental health problems and suicidal behaviours in patients with cancer immediately after diagnosis and in longterm cancer survivors.

Our study had several limitations. First, our results cannot be directly interpreted with respect to the suicide risk of incident cancer patients because the risk for suicide attempts was measured among prevalent cancer patients. However, our findings have important implications concerning supportive care and prevention of suicide among survivors of prevalent cancers. Second, because of the small number of cancer survivors who attempted suicide, the significance of differences in suicide risk according to participant characteristics cannot be examined sufficiently. In particular, the difference in suicide risk according to cancer type may be non-significant due to the small sample size. Further studies are needed to assess the cross-sectional prevalence of psychiatric distress and suicidality for each cancer type. Third, lack of the information in KNANES limited the possibility of exploring the effect of cancer stage on suicide attempts. Despite these limitations, this study has important implications for research on mental health problems in cancer survivors: it is the first to assess the prevalence of, and risk factors for, feelings of sadness and suicide attempts among patients diagnosed with all cancer types and indicates a higher risk of psychiatric distress and suicide in cancer survivors diagnosed early in life, as well as in long-term cancer survivors.

Since the number of cancer survivors is expected to increase as a result of the ageing population and improved survival, the possibility of poor mental health and suicidal behaviour should be constantly monitored in cancer survivors. The results of this study suggest a need for careful assessment and adequate intervention, especially for cancer survivors diagnosed early in life and for long-term cancer survivors.

\section{Author affiliations}

${ }^{1}$ Department of Preventive Medicine, Eulji University College of Medicine, Daejeon, The Republic of Korea

${ }^{2}$ Department of Radiation Oncology, Eulji University College of Medicine, Daejeon,

The Republic of Korea

${ }^{3}$ Department of Preventive Medicine, Korea University College of Medicine, Seoul, The Republic of Korea

${ }^{4}$ Department of Radiation Oncology, Sun Medical Cancer Center, Daejeon, The Republic of Korea

${ }^{5}$ Department of Nursing, Eulji University College of Medicine, Daejeon, The Republic of Korea

Contributors $\mathrm{JL}$ had full access to all of the data in the study and takes responsibility for the integrity of the data. $\mathrm{JL}, \mathrm{JC}$ and $\mathrm{ML}$ were involved in study concept and design. $\mathrm{JL}, \mathrm{JC}, \mathrm{ML}$ and $\mathrm{MK}$ were involved in acquisition of data. $\mathrm{JL}$, $\mathrm{JC}, \mathrm{ML}$ and $\mathrm{J}-\mathrm{YL}$ were involved in analysis and interpretation of data. $\mathrm{JL}, \mathrm{JC}, \mathrm{ML}$ and MK were involved in drafting of the manuscript. JL, Y-JS, SL and SP were involved in critical revision of the manuscript. JC and ML were involved in statistical analysis. JL was involved in study supervision.

Funding This research was supported by Basic Science Research Program through the National Research Foundation (NRF) of Korea funded by the Ministry of Science, ICT \& Future Planning (approval number: NRF-2015R1C1A1A02037283) awarded to JL. This research was partly supported by the Social Science Program (grant number: NRF-2014S1A3A2035458) through the NRF and Korea University grant (K1625561) awarded to MK.

Disclaimer The funders had no role in study design, data collection and analysis, decision to publish or preparation of the manuscript.

\section{Competing interests None declared.}

Patient consent Obtained.

Ethics approval Institutional review board of Eulji University (approval number: EUIRB2016-58).

Provenance and peer review Not commissioned; externally peer reviewed.

Data sharing statement Datasets are available from the corresponding author at jslim@eulji.ac.kr.

Open Access This is an Open Access article distributed in accordance with the Creative Commons Attribution Non Commercial (CC BY-NC 4.0) license, which permits others to distribute, remix, adapt, build upon this work non-commercially, and license their derivative works on different terms, provided the original work is properly cited and the use is non-commercial. See: http://creativecommons.org/ licenses/by-nc/4.0/

(c) Article author(s) (or their employer(s) unless otherwise stated in the text of the article) 2017. All rights reserved. No commercial use is permitted unless otherwise expressly granted. 


\section{REFERENCES}

1. Jung KW, Won YJ, Park S, et al. Cancer statistics in Korea: incidence, mortality and survival in 2005. J Korean Med Sci 2009;24:995-1003.

2. Wedding U, Koch A, Röhrig B, et al. Depression and functional impairment independently contribute to decreased quality of life in cancer patients prior to chemotherapy. Acta Oncol 2008;47:56-62.

3. Crocetti E, Arniani S, Acciai S, et al. High suicide mortality soon after diagnosis among cancer patients in central Italy. Br J Cancer 1998;77:1194-6.

4. Fall K, Fang F, Mucci LA, et al. Immediate risk for cardiovascular events and suicide following a prostate cancer diagnosis: prospective cohort study. PLoS Med 2009;6:e1000197.

5. Misono S, Weiss NS, Fann JR, et al. Incidence of suicide in persons with cancer. J Clin Oncol 2008;26:4731-8.

6. Allebeck P, Bolund C, Ringbäck G. Increased suicide rate in cancer patients. A cohort study based on the Swedish Cancer-Environment Register. J Clin Epidemiol 1989;42:611-6.

7. Dormer NR, McCaul KA, Kristjanson LJ. Risk of suicide in cancer patients in Western Australia, 1981-2002. Med J Aust 2008;188:140-3.

8. Schairer C, Brown LM, Chen BE, et al. Suicide after breast cancer: an international population-based study of 723,810 women. J Natl Cancer Inst 2006;98:1416-9.

9. Fang F, Fall K, Mittleman MA, et al. Suicide and cardiovascular death after a cancer diagnosis. N Engl J Med 2012;366:1310-8.

10. Robinson D, Renshaw C, Okello C, et al. Suicide in cancer patients in South East England from 1996 to 2005: a population-based study. $\mathrm{Br}$ $J$ Cancer 2009;101:198-201.

11. Miccinesi G, Crocetti E, Benvenuti A, et al. Suicide mortality is decreasing among cancer patients in Central Italy. Eur J Cancer 2004;40:1053-7.

12. Ahn E, Shin DW, Cho Sl, et al. Suicide rates and risk factors among Korean cancer patients, 1993-2005. Cancer Epidemiol Biomarkers Prev 2010;19:2097-105.

13. Tanaka $\mathrm{H}$, Tsukuma $\mathrm{H}$, Masaoka $\mathrm{T}$, et al. Suicide risk among cancer patients: experience at one medical center in Japan, 1978-1994. Jpn $J$ Cancer Res 1999;90:812-7.

14. Levi F, Bulliard JL, La Vecchia C. Suicide risk among incident cases of cancer in the Swiss Canton of Vaud. Oncology 1991;48:44-7.

15. Hem E, Loge JH, Haldorsen T, et al. Suicide risk in cancer patients from 1960 to 1999. J Clin Oncol 2004;22:4209-16.

16. Innos K, Rahu K, Rahu M, et al. Suicides among cancer patients in Estonia: a population-based study. Eur J Cancer 2003;39:2223-8.

17. Yousaf U, Christensen ML, Engholm G, et al. Suicides among Danish cancer patients 1971-1999. Br J Cancer 2005;92:995-1000.

18. Storm HH, Christensen N, Jensen OM. Suicides among Danish patients with cancer: 1971 to 1986. Cancer 1992;69:1509-12.

19. Ahn MH, Park S, Lee HB, et al. Suicide in cancer patients within the first year of diagnosis. Psychooncology 2015;24:601-7.

20. Cimprich B, Ronis DL, Martinez-Ramos G. Age at diagnosis and quality of life in breast cancer survivors. Cancer Pract 2002;10:85-93.

21. Wettergren L, Björkholm M, Axdorph U, et al. Determinants of healthrelated quality of life in long-term survivors of Hodgkin's lymphoma. Qual Life Res 2004;13:1369-79.
22. Chirikos TN, Russell-Jacobs A, Cantor AB. Indirect economic effects of long-term breast cancer survival. Cancer Pract 2002;10:248-55.

23. Kiss TL, Abdolell M, Jamal N, et al. Long-term medical outcomes and quality-of-life assessment of patients with chronic myeloid leukemia followed at least 10 years after allogeneic bone marrow transplantation. J Clin Oncol 2002;20:2334-43.

24. Amir M, Ramati A. Post-traumatic symptoms, emotional distress and quality of life in long-term survivors of breast cancer: a preliminary research. J Anxiety Disord 2002;16:191-206.

25. Douchez J, Droz JP, Desclaux B, et al. Quality of life in long-term survivors of nonseminomatous germ cell testicular tumors. J Urol 1993;149:498-501.

26. Joly F, Héron JF, Kalusinski L, et al. Quality of life in long-term survivors of testicular cancer: a population-based case-control study. $J$ Clin Oncol 2002;20:73-80.

27. Casso D, Buist DS, Taplin S. Quality of life of 5-0 year breast cancer survivors diagnosed between age 40 and 49 . Health and quality of life outcomes 2004;1:2(:

28. van Tulder MW, Aaronson NK, Bruning PF. The quality of life of longterm survivors of Hodgkin's disease. Ann Oncol 1994;5:153-8.

29. Weitzner MA, Meyers CA, Stuebing KK, et al. Relationship between quality of life and mood in long-term survivors of breast cancer treated with mastectomy. Support Care Cancer 1997:5:241-8.

30. Dirksen SR. Search for meaning in long-term cancer survivors. J Adv Nurs 1995;21:628-33.

31. Broeckel JA, Thors CL, Jacobsen PB, et al. Sexual functioning in long-term breast cancer survivors treated with adjuvant chemotherapy. Breast Cancer Res Treat 2002;75:241-8.

32. OECD. Health at a glance 2015: OECD indicators. Secondary health at a glance 2015: OECD indicators. 2016 http://www.oecd.org/ health/healthdata.

33. Hoffman KE, McCarthy EP, Recklitis CJ, et al. Psychological distress in long-term survivors of adult-onset cancer: results from a national survey. Arch Intern Med 2009;169:1274-81.

34. Stein KD, Syrjala KL, Andrykowski MA. Physical and psychological long-term and late effects of cancer. Cancer 2008;112(11 Suppl):2577-92.

35. Anguiano L, Mayer DK, Piven ML, et al. A literature review of suicide in cancer patients. Cancer Nurs 2012;35:E14-E26.

36. Kweon S, Kim Y, Jang MJ, et al. Data resource profile: the Korea National Health and Nutrition Examination Survey (KNHANES). Int J Epidemiol 2014:43:69-77.

37. Jung KW, Won YJ, Oh CM, et al. Prediction of cancer incidence and mortality in korea, 2016. Cancer Res Treat 2016;48:451-7.

38. Devika S, Jeyaseelan L, Sebastian G. Analysis of sparse data in logistic regression in medical research: A newer approach. $J$ Postgrad Med 2016;62:26.

39. Recklitis CJ, Lockwood RA, Rothwell MA, et al. Suicidal ideation and attempts in adult survivors of childhood cancer. $J$ Clin Oncol 2006;24:3852-7.

40. Mitchell AJ, Ferguson DW, Gill J, et al. Depression and anxiety in long-term cancer survivors compared with spouses and healthy controls: a systematic review and meta-analysis. Lancet Oncol 2013;14:721-32

41. Pettit JW, Green KL, Grover KE, et al. Domains of chronic stress and suicidal behaviors among inpatient adolescents. J Clin Child Adolesc Psychol 2011;40:494-9. 